\title{
Pengaruh Revaluasi Asset Non Keuangan, Goodwill dan Goodwill- impairment Terhadap Biaya Audit dengan Kepemilikan Keluarga sebagai Variabel Moderasi
}

\author{
Sarlina Sari \\ Universitas Bina Sarana Informatika \\ e-mail: sarlinasari.new@gmail.com

\begin{tabular}{ccc}
\hline Diterima & Direvisi & Disetujui \\
$08-11-2019$ & $02-12-2019$ & $16-01-2020$ \\
\hline
\end{tabular}

\begin{abstract}
Abstrak - Penelitian ini bertujuan untuk menguji pengaruh moderasi kepemilikan keluarga terhadap revaluasi asset non keuangan, goodwill dan goodwill-impairment dan biaya audit. Objek penelitian ini adalah perusahaan non keuangan yang terdaftar di Bursa Efek Indonesia tahun 2011-2015. Hasil regresi menunjukkan bahwa revaluasi asset non keuangan, goodwill dan goodwill-impairment tidak berpengaruh terhadap biaya audit. Akan tetapi, pada perusahaan yang dimiliki oleh keluarga, biaya audit menjadi lebih tinggi jika perusahaan tersebut melakukan revaluasi asset non keuangan. Hasil penelitian ini dapat mendorong regulator untuk (1) menetapkan peraturan terkait besaran maksimal beban penyusutan yang diperbolehkan dalam menyusutkan asset non keuangan yang direvaluasi agar tidak dimanfaatkan untuk menghindari pajak penghasilan (tax avoidance); (2) melakukan sosialisasi standar akuntansi mengenai goodwill dan goodwill impairment, sehingga perusahaan menyadari pentingnya informasi mengenai keandalan nilai goodwill bagi para pemangku kepentingan dalam proses mengambilan keputusan bisnis. Dengan demikian, pelaporan goodwill dan pengungkapan goodwill impairment di laporan keuangan dapat ditingkatkan; (3) menetapkan standar auditing terkait dengan prosedur audit nilai wajar yang memerlukan revaluasi asset non keuangan, goodwill dan goodwill-impairment sehingga auditor lebih aware terhadap reliabilitas nilai wajar yang sulit diobservasi tersebut; (4) menetapkan kebijakan agar perusahaan yang terdaftar di Bursa Efek Indonesia mencantumkan informasi mengenai pemilik akhir perusahaan, sehingga dapat diketahui dengan mudah apakah perusahaan termasuk milik keluarga atau non keluarga.
\end{abstract}

Kata Kunci: revaluasi asset non keuangan; goodwill; goodwill-impairment; biaya audit; kepemilikan keluarga

\begin{abstract}
The purposes of this study are to examine the effect of non-financial assets revaluation, goodwill and goodwill-impairment on audit fees family ownership as moderating variables. This research uses sample of Indonesia Stock Exchange non-financial companies from the years 2011-2015. Regression results show that revaluation of non-financial assets, goodwill and goodwill-impairment have no effect on audit fees. However, companies that family-owned, the audit fee is higher if the companies revalue its nonfinancial assets. The results of this study can encourage regulators to (1) establish regulations related to the maximum amount of depreciation that is allowed to shrink non-financial assets that are revalued so that they are not used to avoid income tax (tax avoidance); (2) socializing accounting standards regarding goodwill and goodwill impairment, so that the company realizes the importance of information regarding the reliability of goodwill value for stakeholders in the process of making business decisions. As such, goodwill reporting and disclosure of goodwill impairments in financial statements can be improved; (3) establish auditing standards related to fair value audit procedures that require revaluation of non-financial assets, goodwill and goodwill-impairments so that auditors are more aware of the reliability of fair value that is difficult to observe; (4) stipulates the policy for companies listed on the Indonesia Stock Exchange to include information regarding the company's final owner, so that it can be easily identified whether the company belongs to family or non-family.
\end{abstract}

Keywords: Non-financial assets revaluation; goodwill, goodwill-impairment; audit fees; family ownership

\section{PENDAHULUAN}

Biaya audit merupakan salah satu isu yang menarik perhatian para peneliti di bidang akuntansi, auditing, dan keuangan dalam beberapa tahun terakhir karena setelah kasus Enron permintaan terhadap audit yang berkualitas semakin meningkat sehingga berpengaruh pada biaya audit (Yuniarti, 2011). Hal 
ini dibuktikan oleh adanya survei khusus yang dilakukan oleh Financial Executives Research Foundation (FERF) pada tahun 2015 mengenai trend biaya audit yang dibayarkan oleh SEC filers, yang hasil surveinya dipublikasikan pada website Journal of Accountancy tahun 2016. Survei tersebut menemukan bahwa median biaya audit tahunan yang dibayarkan oleh 6.490 perusahaan SEC filings meningkat sebesar $3,2 \%$ pada tahun 2015 dibandingkan tahun sebelumnya.

Adanya survei oleh FERF membuktikan pentingnya pengetahuan mengenai biaya audit, khususnya mengenai penyebab variasi biaya audit antar perusahaan dari tahun ke tahun karena biaya audit dapat mencerminkan kualitas audit atas laporan keuangan (Larcker, D. F., 2004). Menurut survei tersebut peningkatan biaya audit bervariasi antara satu perusahaan dengan perusahaan lainnya pada tahun 2015 disebabkan oleh ukuran, jenis, dan karakteristik perusahaan yang diaudit (Tysiac, 2016).

Di Negara berkembang seperti Indonesia, faktor penentu biaya audit menjadi fenomena yang menarik untuk diteliti. Hal ini karena di Negara di Indonesia sebagian besar perusahaan dimiliki dan dikendalikan oleh keluarga (La Porta, R.; Lopez-de-Silanes, F.; \& Shleifer, 1999). Pada perusahaan non keluarga, biaya audit dapat mencerminkan kualitas audit. Sedangkan pada perusahaan keluarga, biaya audit dapat mencerminkan agency cost yang timbul akibat adanya insentif pemegang saham mayoritas untuk memaksimalkan keuntungan sendiri dengan mengorbankan kepentingan pemegang saham non pengendali (Khan, A.; Muttakin, M. B \& Siddique, 2015).

Penelitian (Fei, Yao, Percy, \& Hu, 2015) dan penelitian (Ghosh \& Wang, 2016) telah membuktikan bahwa faktor risiko inherent juga merupakan salah satu faktor penentu biaya audit. Dalam audit laporan keuangan, risiko inherent paling mungkin terjadi pada revaluasi asset non keuangan, goodwill dan goodwill-impairment, atau dalam situasi yang membutuhkan tingkat judgment yang tinggi. Hal ini karena revaluasi asset non keuangan, goodwill dan goodwill-impairment merupakan estimasi akuntansi yang sulit diverifikasi dan belum diatur dengan jelas dalam standar akuntansi. Namun, estimasi ini sering digunakaan oleh manajer sehingga laporan keuangan menjadi rentan terhadap diskresi dan perilaku oportunistik manajemen. Misalnya, PSAK 22 "Kombinasi Bisnis" yang hanya menjelaskan bahwa goodwill merupakan bargain purchase antara pihak yang mengkombinasikan bisnisnya dengan menilai kembali nilai wajarnya pada saat akuisisi. Dalam PSAK ini belum dinyatakan dengan jelas berapa besaran goodwill yang seharusnya diakui pada saat merger atau akuisi. Ini tentu saja membutuhkan estimasi manajemen yang dianggap oleh auditor sebagai estimasi akuntansi yang kompleks untuk mereka assess kewajarannya. Begitu pula halnya ketika manajemen menentukan besaran nilai impairment atas goodwill yang mereka miliki.

Selain itu, komponen laporan keuangan yang mungkin harus menggunakan estimasi akuntansi yang kompleks antara lain asset non keuangan yang diukur menggunakan nilai wajar pada saat direvaluasi yang harga wajar asset tersebut tidak tersedia di pasar aktif, sehingga memerlukan judgment manajemen atau appraisal yang mungkin saja mengandung bias yang disengaja maupun yang tidak disengaja. Oleh karena itu auditor harus melakukan pekerjaan audit dengan lebih intensif dan hati-hati agar auditor dapat menyatakan opininya sebagaimana mestinya atas suatu laporan keuangan yang telah diaudit.

Seiring peningkatan estimasi akuntansi yang kompleks dalam laporan keuangan sehingga mempengaruhi kualitas pelaporan keuangan saat ini (Barth, 2006), membutuhkan pemahaman auditor yang lebih baik dalam melakukan pekerjaan audit atas laporan keuangan yang menggunakan estimasi tersebut. Selain itu, penelitian terdahulu menemukan bahwa auditor memiliki valuation skill yang terbatas untuk menilai estimasi nilai wajar, khususnya nilai wajar yang ditentukan menggunakan asumsi manajemen (Kumarasiri, J. \& Fisher, 2011), sehingga memeriksa nilai wajar dari aset non keuangan, goodwill dan goodwill-impairment menyebabkan peningkatan risiko audit dan taskdifficulty dari pekerjaan auditor. Dengan adanya tambahan risiko tersebut, tambahan biaya audit dibebankan oleh auditor kepada klien untuk mengkompensasi auditor dari potensi kerugian yang berkaitan dengan klien yang berisiko tinggi tersebut (Calderon, T. G.; Wang, L. \& Klenotic, 2012).

Penelitian ini memiliki dua kontribusi. Pertama, penelitian ini merupakan replikasi penelitian Yao, Percy, dan Hu (2015) dalam konteks pasar modal yang sedang berkembang, yaitu Indonesia. Namun, penelitian ini menambahkan pengukuran dari estimasi akuntansi yang kompleks yang sebelumnya hanya terbatas pada penggunaan nilai wajar saat revaluasi asset non keuangan, dengan pengukuran lainnya dari penelitian Ghosh dan Wang (2016) yaitu goodwill, dan goodwill-impairment. Alasannya, revaluasi asset non keuangan, goodwill dan goodwill-impairment merupakan faktor yang sama-sama berkaitan dengan estimasi akuntansi yang kompleks yang memungkinkan mengandung diskresi manajemen sehingga akan menimbulkan masalah agensi.

Kedua, penelitian ini menambah variabel struktur 
kepemilikan keluarga yang memoderasi pengaruh revaluasi asset non keuangan, goodwill dan goodwill-impairment terhadap biaya audit. Di Indonesia, sebagian besar kepemilikan perusahaan terkonsentrasi pada kepemilikan keluarga (La Porta, R.; Lopez-de-Silanes, F.; \& Shleifer, 1999). Terkait dengan tujuan penggunaan estimasi akuntansi yang kompleks, terdapat kemungkinan perusahaan keluarga akan menyembunyikan motivasi mereka dalam melakukan revaluasi asset non keuangan, goodwill dan goodwill-impairment untuk tujuan tertentu, misalnya perusahaan melakukan upward revaluation untuk tujuan penghindaran pajak. Motivasi penghindaran pajak tersebut semakin bersifat oportunis karena didukung oleh sistem pengendalian internal perusahaan yang lemah. Hal ini akan meningkatkan risiko bagi auditor sehingga auditor membebankan biaya audit yang lebih tinggi. Di sisi lain, perusahaan keluarga mungkin akan mempertimbangkan prinsip keberlanjutan usaha dan cenderung menjaga reputasi perusahaan, sehingga auditor dapat mempercayai bahwa penggunaan estimasi akuntansi yang kompleks tersebut karena didasari oleh tujuan relevansi laporan keuangan dan biaya audit menjadi lebih rendah.

\section{A. Kajian Pustaka}

Teori keagenan dan teori tata kelola perusahaan merupakan teori yang dapat digunakan untuk menggambarkan konflik keagenan yang timbul akibat penggunaan estimasi akuntansi yang kompleks dalam laporan keuangan (Jensen, M., C. \& Meckling. W., 1976). Konflik keagenan harus dapat diminimalisir agar pemegang saham merasa terlindungi. Untuk meminimalisir konflik keagenan tersebut, perusahaan harus memiliki tata kelola yang baik. Salah satunya dengan melibatkan pihak ketiga yang independen dan kompeten yaitu auditor.

Auditor harus memeriksa kewajaran laporan agar dapat memberikan opininya atas laporan keuangan yang diaudit dengan benar. Oleh karena itu, auditor harus mempertimbangkan berbagai faktor, salah satunya risiko inherent yang timbul dari penggunaan estimasi yang kompleks oleh manajemen. Jika klien menggunakan estimasi yang kompleks dalam laporan keuangannya, maka auditor harus membuat perencanaan audit dan melakukan substantive test yang sangat detil untuk memastikan kewajaran estimasi tersebut.

\section{B. Kerangka Pemikiran}

Ketidakpastian estimasi dan kompleksitas yang melekat dalam laporan keuangan telah meningkat dalam beberapa dekade terakhir (Christensen, B. E.; Glover, S. M \& Wood, 2012). Hal ini merupakan konsekuensi dari perkembangan standar akuntansi yang lebih principle-based dan peningkatan penggunaan pengukuran nilai wajar.

Namun, standar-setter tentu tidak bermaksud untuk mengenalkan ketidakpastian yang tidak perlu. Melainkan untuk meningkatkan relevansi item laporan keuangan. Dalam IFRS 13, standar-setter menganjurkan hierarki nilai wajar yang memaksimalkan penggunaan input yang dapat diobservasi dan meminimalkan penggunaan input yang tidak dapat diobservasi (IASB, 2011 paragraf 67). Meskipun standar-setter bermaksud untuk membatasi ketidakpastian estimasi, standar kontemporer masih mentolerir ketidakpastian estimasi yang cukup besar dalam laporan keuangan. Oleh karena itu, auditor perlu melakukan audit yang berkualitas agar kompleksitas dan ketidakpastian estimasi akuntansi tersebut tidak mengandung tingkat subjetivitas yang tinggi yang akan merugikan pemegang saham.

\section{Pengembangan Hipotesis}

\section{Revaluasi Aset Non-Keuangan dan Biaya Audit}

Akuntansi nilai wajar akan meningkatkan biaya audit sebagai akibat meningkatnya biaya agensi yang berkaitan dengan estimasi nilai wajar. Penyebab utama adalah pasar modal tidak selalu sempurna atau lengkap, dan sering memerlukan asumsi manajemen atau model untuk menentukan nilai wajar dibandingkan memperolehnya dari pasar likuid. Hal yang paling penting adalah apakah nilai wajar tersebut telah diukur secara andal.

Banyak kasus yang berkaitan dengan nilai wajar asset non keuangan khususnya pada saat pasar aktif tidak tersedia. Nilai wajar berdasarkan 'mark-tomodel' diukur berdasarkan asumsi manajemen dan memerlukan pertimbangan appraisal yang menyebabkan bias unintentional dan intentional (Yao D., F; Percy, M.; \& Hu, 2015). Selain itu juga banyak penelitian terdahulu membuktikan bahwa terdapat bias manajemen dalam estimasi nilai wajar, sehingga meningkatkan risiko audit (Beaver, W. \& Venkatachalam, 2003).

Berkaitan dengan biaya audit, beberapa penelitian telah menguji penentuan biaya audit oleh auditor sehubungan dengan risiko audit dan menemukan bahwa auditor merespon klien yang berisiko tinggi dengan menentukan biaya audit yang lebih tinggi karena meningkatnya inherent risk yang mengharuskan auditor melakukan upaya audit yang lebih tinggi untuk mengurangi detection risk (Bell, Landsman, \& Shackelford, 2016). Selain itu, perusahaan di Indonesia belum terlalu banyak yang melakukan revaluasi asset non keuangan. Hal ini disebabkan oleh mahalnya biaya yang harus dibayarkan kepada jasa appraisal dan adanya persepsi manajer akan meningkatkan biaya audit (Ramadhani, 2016). Oleh karena itu, hipotesis 
pertama penelitian ini adalah sebagai berikut:

Hipotesis 1: Biaya audit pada perusahaan yang melakukan revaluasi aset non keuangan lebih tinggi dibandingkan pada perusahaan yang tidak melakukan revaluasi aset non keuangan.

\section{Goodwill, Goodwill-impairment dan Biaya Audit}

Auditor memerlukan audit effort yang signifikan dan penilaian audit yang sulit terhadap goodwill dan goodwill-impairment karena beberapa alasan berikut (Ghosh \& Wang, 2016). Pertama, auditor harus mengevaluasi kewajaran estimasi manajemen, apakah asumsi konsisten dengan kondisi pasar, rencana dan strategi manajemen, pengalaman masa lalu, asumsi laporan keuangan lainnya, dan risiko yang terkait dengan arus kas masa depan berdasarkan pedoman pemeriksaan (AU bagian 341). Kedua, karena standar akuntansi mengharuskan goodwill dan aset jangka panjang lainnya ditinjau penurunannya jika terjadi peristiwa atau perubahan keadaan yang mengindikasikan bahwa nilai tercatat aset tersebut tidak dapat diperoleh, auditor harus waspada untuk setiap perubahan yang dapat mempengaruhi pemulihan dari aset. Ketiga, auditor perlu mempertimbangkan proses dan kontrol yang digunakan oleh manajemen untuk mengembangkan estimasi dan kemudian memeriksa data internal dan eksternal yang tepat dalam mendukung asumsi signifikan (AU 342). Keempat, auditor harus memahami bisnis, strategi saat ini dalam memanfaatkan aset, dan kemungkinan keberhasilan di masa depan. Terakhir, ketika aset tersebut terjadi penurunan dan kerugiannya dihitung, auditor harus mengevaluasi kewajaran penentuan manajemen dari besarnya biaya penurunan tersebut (AU 328). Berdasarkan beberapa alasan yang kuat seperti dijelaskan sebelumnya, auditor diprediksi akan membebankan biaya audit yang lebih besar kepada klien yang memiliki akun goodwill dan goodwill-impairment untuk mengkompensasi hal-hal tersebut. Oleh karena itu, hipotesis kedua penelitian ini adalah sebagai berikut:

Hipotesis 2a: Goodwill berpengaruh positif terhadap biaya audit.

Hipotesis 2b: Biaya audit pada perusahaan yang melakukan goodwill-impairment lebih tinggi dibandingkan pada perusahaan yang tidak melakukan goodwill-impairment.

\section{Revaluasi Aset Non Keuangan, Goodwill, Goodwill-impairment, Biaya Audit dan Kepemilikan Keluarga}

Seperti yang telah dijelaskan sebelumnya bahwa penggunaan nilai wajar pada saat revaluasi aset non keuangan, pengakuan goodwill, dan goodwillimpairment cenderung memiliki potensi fraud karena terdapat penggunaan estimasi nilai wajar yang kompleks sehingga sulit diverifikasi kewajarannya. Hal ini menjadi kesulitan tersendiri bagi auditor karena nilai wajar tersebut memiliki ketidakpastian dalam estimasi, volatilitas di pasar keuangan, risiko ekonomi makro, dan bias manajerial (Griffith, 2015).

Selanjutnya, penggunaan nilai wajar tersebut bagi perusahaan keluarga, memiliki kemungkinan diskresi dan perilaku oportunistik. Hal ini karena keluarga biasanya memiliki insentif yang kuat untuk mengambil alih kekayaan dari pemegang saham minoritas, dan mengejar kepentingan mereka sendiri dengan mengorbankan pemegang saham nonpengendali (Faccio, M., \& Lang, 2002). Salah satunya dengan cara revaluasi aset non keuangan untuk tujuan penghindaran pajak atau auditor harus memverifikasi estimasi nilai wajar goodwill, melibatkan valuation experts untuk verifikasi independen dari estimasi nilai wajar tersebut, dan menghadapi manipulasi oleh manajemen terkait dengan waktu dari pengakuan goodwill impairment. Selain itu, perusahaan keluarga sering dikategorikan sebagai perusahaan yang kurang professional karena beberapa alasan, yaitu perusahaan keluarga yang mayoritas manajemen kuncinya merupakan kerabat cenderung tidak bisa memisahkan antara kepentingan keluarga dan kepentingan perusahaan, lebih mengedepankan hubungan keluarga daripada mengutamakan kinerja perusahaan, dan sistem pengendalian internal perusahaan keluarga cenderung lemah dan tidak terkontrol agar hubungan keluarga antar manajer atau karyawan tetap terjaga (Hidayat, 2014). Hal ini tentu akan meningkatkan risiko audit. Auditor dituntut untuk melakukan proses audit lebih intensif dan akan membebankan biaya audit yang lebih tinggi (Ho, J. L., \& Kang, 2013). Di sisi lain, perusahaan keluarga umumnya akan menghindari kegiatan fraud dan perilaku oportunistik untuk tujuan menjaga keberlanjutan perusahaan dan cenderung menjaga reputasi perusahaan. Hal ini menyebabkan auditor berasumsi bahwa meskipun perusahaan keluarga menggunakan revaluasi asset non keuangan, goodwill dan goodwill-impairment, risiko audit pada peruhaan keluarga cenderung rendah dan akan membebankan biaya audit yang rendah pula sehingga hipotesis keempat penelitian ini sebagai berikut:

Hipotesis 3a: Pada perusahaan keluarga yang melakukan revaluasi asset non keuangan menyebabkan biaya audit lebih tinggi atau lebih rendah.

Hipotesis 3b: Pada perusahaan keluarga yang memiliki goodwill menyebabkan biaya audit lebih 
tinggi atau lebih rendah.

Hipotesis 3c: Pada perusahaan keluarga yang melakukan goodwill-impairment menyebabkan biaya audit lebih tinggi atau lebih rendah.

\section{METODOLOGI PENELITIAN}

\section{A. Model Penelitian}

Penelitian ini menggunakan Model (1) dan Model (2) yang dikembangkan dari (Yao D., F; Percy, M. \& Hu, 2015) dan (Ghosh \& Wang, 2016). Model (1) digunakan untuk menguji hipotesis tanpa variabel moderasi, sedangkan Model (2) digunakan menguji hipotesis dengan variabel moderasi. Model

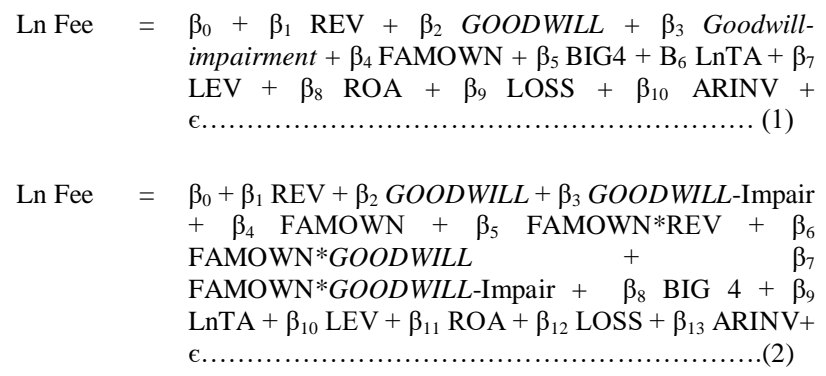

penelitian ini adalah sebagai berikut:

\section{Di mana:}

Ln FEE adalah logaritma natural dari biaya audit, REV bernilai 1 jika perusahaan mengukur aset nonkeuangan (PPE, aset tak berwujud dan properti investasi) pada nilai wajar, dan 0 jika lainnya; GOODWILL adalah rasio goodwill terhadap total aset; GOODWILL-Impair adalah perusahaan yang melakukan goodwill-impairment, di mana 1 jika perusahaan mencatat impairment atas goodwill dan 0 jika lainnya; FAMOWN adalah kepemilikan keluarga di mana bernilai 1 jika kepemilikan terbesar perusahaan adalah keluarga dan 0 jika sebaliknya; BIG 4 adalah ukuran auditor yaitu bernilai 1 jika perusahaan menggunakan jasa auditor Big 4, dan 0 jika lainnya; LnTA adalah logaritma natural dari total aset; LEV adalah rasio total hutang terhadap total aset; ROA adalah rasio laba operasional terhadap total aset; LOSS bernilai1 jika perusahaan mengalami kerugian, dan 0 jika lainnya; dan ARINV adalah rasio piutang dan persediaan terhadap total aset.

\section{B. Populasi Penelitian}

Populasi yang digunakan dalam penelitian ini adalah seluruh perusahaan non keuangan yang terdaftar di Bursa Efek Indonesia (BEI) tahun 2011-2015 karena perusahaan di Indonesia baru mulai mengungkapkan informasi biaya audit dalam laporan tahunannya sejak tahun 2011 (Veronica \& Anggraita, 2016). Sampel tidak termasuk perusahaan sektor keuangan (seperti bank, perusaahaan asuransi dan investasi) karena industri ini memiliki stuktur laporan keuangan dan kebijakan akuntansi yang berbeda terkait beberapa hal, seperti pengakuan pendapatan dan beban, dan penilaian terhadap asset (Khikia, 2015). Perusahaan yang menjadi sampel dalam penelitian ini dipilih berdasarkan kriteria tertentu (purposive sampling) yang bertujuan untuk mendapatkan sampel yang representative sesuai dengan kriteria yang ditentukan dan diperoleh sebanyak 171 observasi.

\section{HASIL DAN PEMBAHASAN}

Penelitian ini bertujuan untuk menguji pengaruh moderasi kepemilikan keluarga terhadap revaluasi asset non keuangan, goodwill dan goodwillimpairment dan biaya audit. Hasil pengujian hipotesis ditampilkan pada Tabel 1.

\section{1) Analisis Hasil Regresi Variabel Utama}

Hasil regresi Model (1) menunjukkan menunjukkan bahwa perusahaan yang melakukan revaluasi asset non keuangan tidak memiliki biaya audit yang lebih tinggi dibandingkan perusahaan yang tidak melakukan revaluasi asset non keuangan, sehingga hasil penelitian ini menolak Hipotesis $1(\mathrm{H} 1)$. Hal ini disebabkan oleh kondisi di Indonesia di mana perusahaan yang terdaftar di Bursa Efek Indonesia masih sedikit yang melakukan revaluasi asset non keuangan. Meskipun memiliki relevansi yang tinggi, revaluasi asset non keuangan dalam praktiknya lebih rumit karena perusahaan harus mengeluarkan biaya yang besar untuk membayar jasa appraisal (Ramadhani, 2016). Selain itu, rata-rata perusahaan sampel adalah perusahaan besar. Perusahaan besar cenderung menerapkan revaluasi ke atas (upward revaluation) terhadap aset non-keuangannya, yang berarti bahwa selisih antara nilai buku dan nilai revaluasi akan menghasilkan peningkatan saldo laba komprehensif perusahaan. Hal ini menyebabkan perusahaan besar tidak bisa menghindari peraturan perpajakan. Adanya peraturan Perpajakan PMK No. 79/PMK.03/2008 yang menetapkan pajak final sebesar $10 \%$ terhadap selisih nilai revaluasi aset memungkinkan perusahaan memilih model biaya untuk menghindari risiko terkena peraturan perpajakan yang menyebabkan kenaikan pembayaran pajak.

Kondisi ini menyebabkan auditor tidak terlalu memperhatikan dampak dari revaluasi asset non keuangan terhadap pengujian audit yang akan dilakukannya sehingga tidak berpengaruh terhadap biaya audit. Hasil penelitian ini tidak konsisten baik dengan hasil penelitian (Yao D., F; Percy, M. \& Hu, 2015) maupun dengan hasil penelitian (Goncharov, 
Riedl, \& Sellhorn, 2012).

Tabel 1

Hasil Pengujian Hipotesis

\begin{tabular}{|c|c|c|c|c|c|c|}
\hline \multirow{2}{*}{ Ln Fee } & \multirow{2}{*}{ Hipotesis } & \multirow{2}{*}{$\begin{array}{l}\text { Expected } \\
\text { Sign }\end{array}$} & \multicolumn{2}{|c|}{ Model 1} & \multicolumn{2}{|c|}{ Model 2} \\
\hline & & & Coef. & Prob & Coef. & Prob \\
\hline \multicolumn{7}{|l|}{ Main Variabel } \\
\hline REV & $\mathrm{H} 1$ & $(+)$ & .002 & 0.495 & -1.512 & $0.032 * *$ \\
\hline GOODWILL & $\mathrm{H} 2$ & $(+)$ & -.000 & 0.450 & .000 & 0.500 \\
\hline GOODWILL-Impair & $\mathrm{H} 2$ & $(+)$ & .023 & 0.447 & .874 & 0.198 \\
\hline ASCORE & & & -.317 & 0.255 & -.623 & 0.307 \\
\hline FAMOWN & & & -.087 & 0.692 & -.207 & 0.646 \\
\hline FAMOWN*REV & $\mathrm{H} 4$ & $(+) /(-)$ & & & .600 & $0.043 * *$ \\
\hline FAMOWN $* G O O D W I L L$ & $\mathrm{H} 4$ & $(+) /(-)$ & & & -.009 & 0.454 \\
\hline $\begin{array}{l}\text { FAMOWN*GOODWILL- } \\
\text { Impair }\end{array}$ & $\mathrm{H} 4$ & $(+) /(-)$ & & & -.358 & 0.139 \\
\hline \multicolumn{7}{|l|}{ Control Variabel } \\
\hline BIG 4 & & $(+)$ & .340 & $0.042 * *$ & .344 & $0.040 * *$ \\
\hline LnTA & & $(+)$ & .495 & $0.000 * * *$ & .488 & $0.000^{* * * *}$ \\
\hline LEV & & $(+)$ & .437 & $0.091 *$ & .503 & $0.064 *$ \\
\hline ROA & & $(+)$ & .825 & 0.221 & .608 & 0.287 \\
\hline LOSS & & $(+)$ & .260 & 0.131 & .176 & 0.229 \\
\hline ARINV & & $(+)$ & .441 & 0.173 & .499 & 0.145 \\
\hline $\mathrm{N}$ & 171 & & & & 171 & \\
\hline R-square (overall) & 0.4906 & & & & 0.5186 & \\
\hline Wald Chi2 (11) & 64.80 & & & & & \\
\hline Wald Chi2 (17) & & & & & 73.39 & \\
\hline Prob $>$ Chi2 & 0.000 & & & & 0.000 & \\
\hline
\end{tabular}

* Two-tailed probabilities.

* significant at the $10 \%$ level (two-tailed

* sig

test).

** significant at the $5 \%$ level (two-tailed

est).

*** significant at the $1 \%$ level (two-

tailed test).

Sumber: SPSS 2015

Hasil regresi Model (1) menunjukkan bahwa goodwill tidak berpengaruh terhadap biaya audit, sehingga hasil penelitian ini menolak Hipotesis 2a (H2a). Hal ini disebabkan oleh jumlah goodwill di Indonesia yang masih sangat rendah dibanding negara maju seperti Amerika Serikat. Artinya, perusahaan di Indonesia masih jarang melakukan kombinasi bisnis. Oleh karena jumlahnya tidak signifikan, maka auditor tidak mengganggap goodwill sebagai asset yang membutuhkan pengujian audit yang signifikan, sehingga tidak berpengaruh terhadap biaya audit. Hasil penelitian ini bertolak belakang dengan hasil penelitian (Ghosh \& Wang, 2016).

Hasil regresi Model (1) menunjukkan bahwa biaya audit pada perusahaan yang melakukan goodwillimpairment tidak lebih tinggi dibandingkan pada perusahaan yang tidak melakukan goodwill- impairment, sehingga hasil penelitian ini menolak Hipotesis 2b (H2b). Hal ini karena goodwillimpairment terjadi secara tidak teratur setiap tahun dengan jumlah yang berbeda-beda, dan memungkinkan jumlah penurunan yang besar yang akan mengakibatkan volatilitas laba yang dilaporkan meningkat. Kerugian penurunan nilai goodwill juga dapat menandakan bahwa perusahaan akan mengalami kerugian atas nilai ekonomi masa depan dan memiliki pengaruh terhadap aset dan pendapatan perusahaan (Nuryani, N \& Samsudiono, 2013). Alasan tersebut mungkin menyebabkan kebanyakan manajer enggan melakukan impairment terhadap goodwill. Oleh karena jumlahnya tidak signifikan, maka auditor tidak mengganggap goodwill-impairment sebagai hal yang membutuhkan pengujian audit yang signifikan, sehingga tidak berpengaruh terhadap biaya audit. Hasil penelitian ini bertolak belakang dengan hasil penelitian (Ghosh \& Wang, 2016).

\section{2) Analisis Hasil Regresi Variabel Moderasi}

Hasil regresi Model (2) menunjukkan bahwa perusahaan yang melakukan revaluasi asset non keuangan memiliki biaya audit yang lebih rendah (negatif) dibandingkan perusahaan yang tidak melakukan revaluasi asset non keuangan. Hal ini karena mayoritas perusahaan yang melakukan revaluasi asset non keuangan di Indonesia menggunakan jasa appraisal (penilai independen) untuk menentukan nilai wajar. Standar auditing mengakui peran ahli tersebut. International Standard on Auditing 500: Audit Evidence (International Federation of Accountants, 2010) menyatakan bahwa auditor dapat menerima penilaian spesialis yang dipekerjakan oleh manajemen sebagai bukti audit yang sesuai. Hal ini menunjukkan adanya peran substitusi antara appraisal dan auditor, yaitu appraisal dapat memberikan keahlian dan wawasan mengenai estimasi nilai wajar asset non keuangan yang berpotensi mengurangi upaya yang diperlukan oleh auditor untuk mencapai tingkat risiko audit tertentu (Goncharov, I.; Riedl, E., J \& Sellhorn, 2011). Selain itu, penelitian sebelumnya menemukan bahwa asimetri informasi menurun pada perusahaan properti yang menggunakan jasa appraisal (versus manajemen) karena secara umum penggunaan nilai wajar pada asset non keuangan akan meningkatkan eksposur dari berbagai pihak sehingga akan mengurangi biaya monitoring (Goncharov, I.; Riedl, E., J \& Sellhorn, 2011). Berdasarkan pernyataan tersebut, auditor menetapkan biaya audit yang lebih rendah pada perusahaan yang melakukan revaluasi asset non keuangan.

Hasil regresi Model (2) menunjukkan bahwa perusahaan keluarga yang melakukan revaluasi asset non keuangan menyebabkan biaya audit menjadi lebih tinggi (atau less negative), sehingga hasil 
penelitian ini menerima Hipotesis 3a (H3a). Hasil penelitian ini mendukung pendapat Ho \& Kang (2013) yang menyatakan bahwa adanya insentif yang kuat dari perusahaan keluarga terlibat dalam kegiatan fraud atau oportunistik yang merugikan pihak tertentu dan akan meningkatkan risiko audit. Dalam hal revaluasi asset non keuangan ke atas (upward revaluation), beban penyusutan akan meningkat sehingga akan mengurangi laba tahun berjalan. Perusahaan keluarga cenderung mengambil keuntungan ini untuk menghindari pajak penghasilan (tax avoidance). Selain itu, perusahaan keluarga sering dikategorikan sebagai perusahaan yang kurang professional karena beberapa alasan, yaitu perusahaan keluarga yang mayoritas dikendalikan oleh kerabat cenderung tidak bisa memisahkan antara kepentingan keluarga dan kepentingan perusahaan, lebih mengedepankan hubungan keluarga daripada mengutamakan kinerja perusahaan, dan sistem pengendalian internal perusahaan keluarga cenderung lemah dan tidak terkontrol agar hubungan keluarga di dalam perusahaan tetap terjaga (Hidayat, 2014). Hal ini tentu akan meningkatkan risiko audit. Oleh karena itu, auditor dituntut untuk melakukan proses audit lebih intensif terkait kewajaran nilai revaluasi asset non keuangan pada perusahaan keluarga dan akan membebankan biaya audit yang lebih tinggi.

Hasil regresi Model (2) menunjukkan bahwa pada perusahaan keluarga, goodwill tidak berpengaruh terhadap biaya audit, sehingga hasil penelitian ini menolak Hipotesis 3b (H3b). Hal ini mungkin disebabkan oleh jumlah goodwill dalam laporan keuangan perusahaan di Indonesia tidak signifikan. Oleh karena jumlahnya tidak signifikan, maka auditor tidak mengganggap goodwill sebagai asset yang membutuhkan pengujian audit yang signifikan pula, sehingga tidak berpengaruh terhadap biaya audit.

Hasil regresi Model (2) menunjukkan bahwa pada perusahaan keluarga yang memiliki goodwillimpairment tidak menyebabkan biaya audit lebih tinggi atau lebih rendah, sehingga hasil penelitian ini menolak Hipotesis 3c (H3c). Hal ini karena jumlah perusahaan yang melakukan goodwill-impairment di Indonesia masih sedikit. Auditor menganggap bahwa akun tersebut tidak akan memberikan dampak yang material pada laporan keuangan sehingga tidak memerlukan pengujian audit yang intensif. Oleh karena itu, goodwill-impairment pada perusahaan keluarga tidak menyebabkan biaya audit lebih tinggi atau lebih rendah.

\section{3) Analisis Hasil Regresi Variabel Kontrol}

Berdasarkan hasil pengujian variabel kontrol yang ditampilkan pada Tabel 4.3 dapat diketahui bahwa ukuran KAP, ukuran perusahaan, dan risiko perusahaan berpengaruh positif terhadap biaya audit. Akan tetapi, profitabilitas, loss, dan kompleksitas perusahaan tidak berpengaruh terhadap biaya audit. Hasil regresi Model (1) dan Model (2) menunjukkan bahwa ukuran KAP berpengaruh positif terhadap biaya audit yang sesuai dengan prediksi awal. Hal ini berarti bahwa auditor Big 4 akan membebankan biaya audit yang lebih tinggi karena mereka memiliki reputasi dan kredibilitas yang tinggi sehingga mampu melakukan audit yang lebih berkualitas. Hasil penelitian ini konsisten dengan hasil penelitian sebelumnya (Khikia, 2015).

Hasil regresi Model (1) dan Model (2) menunjukkan bahwa ukuran perusahaan berpengaruh positif terhadap biaya audit yang sesuai dengan prediksi awal. Hal ini karena semakin besar ukuran perusahaan, semakin lama proses audit, dan akibatnya biaya audit semakin tinggi. Dengan kata lain, klien besar akan memiliki lebih banyak transaksi. Oleh karena itu, auditor harus melakukan proses dan prosedur audit yang lebih rinci. Hal ini menyebakan biaya audit yang lebih tinggi. Hasil penelitian ini konsisten dengan hasil penelitian terdahulu (Khikia, 2015); (Meshari, 2008).

Hasil regresi Model (1) dan Model (2) menunjukkan bahwa risiko perusahaan berpengaruh positif terhadap biaya audit yang sesuai dengan prediksi awal. Hal ini berarti bahwa semakin tinggi rasio leverage, semakin besar tanggung jawab auditor dalam pekerjaan audit, sehingga auditor pantas mendapat imbalan lebih tinggi untuk mengimbangi risiko tersebut. Hasil penelitian ini konsisten dengan hasil penelitian (Khikia, 2015).

Hasil regresi Model (1) dan Model (2) menunjukkan bahwa profitabilitas tidak berpengaruh terhadap biaya audit. Hal ini berarti perusahaan di Indonesia tidak membayar auditor dengan biaya audit yang lebih tinggi meskipun perusahaan sedang memperoleh laba. Hasil penelitian ini tidak konsisten dengan penelitian (Khikia, 2015) dan (Simunic, 1980).

Hasil regresi Model (1) dan Model (2) menunjukkan bahwa loss tidak berpengaruh terhadap biaya audit. Artinya, meskipun perusahaan sedang mengalami kerugian, auditor tidak akan meningkatkan atau mengurangi biaya audit yang seharusnya mereka terima untuk mengaudit laporan keuangan perusahaan. Selain itu, hal ini mungkin saja disebabkan oleh jumlah perusahaan yang mengalami kerugian hanya $10 \%$ dari total perusahaan sampel sehingga pengaruhnya tidak signifikan.

Hasil regresi menunjukkan Model (1) dan Model (2) bahwa kompleksitas perusahaan tidak berpengaruh terhadap biaya audit. Hasil penelitian ini konsisten dengan hasil penelitian (Paramita, 2016) yang 
menemukan bahwa kompleksitas audit tidak berpengaruh terhadap biaya audit.

\section{KESIMPULAN}

Hasil regresi menunjukkan bahwa revaluasi asset non keuangan, goodwill dan goodwill-impairment tidak berpengaruh terhadap biaya audit. Akan tetapi, pada perusahaan yang dimiliki oleh keluarga, biaya audit menjadi lebih tinggi jika perusahaan tersebut melakukan revaluasi asset non keuangan. Hasil penelitian ini antara lain dapat mendorong regulator agar (1) menetapkan peraturan terkait besaran maksimal beban penyusutan yang diperbolehkan dalam menyusutkan asset non keuangan yang direvaluasi agar tidak dimanfaatkan untuk menghindari pajak penghasilan (tax avoidance); (2) melakukan sosialisasi standar akuntansi mengenai goodwill dan goodwill impairment, sehingga perusahaan menyadari pentingnya informasi mengenai keandalan nilai goodwill bagi para pemangku kepentingan dalam proses mengambilan keputusan bisnis. Dengan demikian, pelaporan goodwill dan pengungkapan goodwill impairment di laporan keuangan dapat ditingkatkan; (3) menetapkan standar auditing terkait dengan prosedur audit nilai wajar yang memerlukan estimasi akuntansi yang kompleks sehingga auditor lebih aware terhadap reliabilitas nilai wajar yang sulit diobservasi tersebut; (4) menetapkan kebijakan agar perusahaan yang terdaftar di Bursa Efek Indonesia mencantumkan informasi mengenai pemilik akhir perusahaan, sehingga dapat diketahui dengan mudah apakah perusahaan termasuk milik keluarga atau non keluarga.

\section{REFERENSI}

Barth, M. E. (2006). Including Estimates of the Future in Today's Financial Statements. Accounting Horizons, 20.

Beaver, W. \& Venkatachalam, M. (2003). Differential Pricing of Components of Bank Loan Fair Values. Journal of Accounting, Audit and Finance, 18(1).

Bell, T. B., Landsman, W. R., \& Shackelford, D. A. (2016). Auditors ' Perceived Business Risk and Audit Fees: Analysis and Evidence Stable URL: $\quad$ http://www.jstor.org/stable/2672944 Auditors 'Perceived Business Risk and Audit Fees: Analysis and Evidence. 39(1), 35-43.

Calderon, T. G.; Wang, L. \& Klenotic, T. (2012). Past Control Risk and Current Audit Fees. Managerial Auditing Journal, 27(7).

Christensen, B. E.; Glover, S. M \& Wood, D. A. (2012). Extreme Estimation Uncertainty In Fair Value Estimates: Implications For Audit Assurance. Auditing: A Journal of Practice \&
Theory, 31(1).

Faccio, M., \& Lang, L. H. P. (2002). The ultimate ownership of Western European corporations. Journal of Financial Economics, 65(3).

Fei, D., Yao, T., Percy, M., \& Hu, F. (2015). Journal of Contemporary Accounting \& Economics Fair value accounting for non-current assets and audit fees: Evidence from Australian companies. Journal of Contemporary Accounting \& Economics, 11(1), 31-45. https://doi.org/10.1016/j.jcae.2014.12.003

Ghosh, A. Al, \& Wang, J. (2016). Audit Quality of Complex Accounting Estimates: Evidence from Audit Tests of Goodwill and Special Charges Audit Quality of Complex Accounting Estimates: Evidence from Audit Tests of Goodwill and Special Charges. 1-57.

Goncharov, I.; Riedl, E., J \& Sellhorn, T. (2011). No TitleFair Value and Audit Fees. Accounting, Management Control Department Research Seminar.

Goncharov, I., Riedl, E. J., \& Sellhorn, T. (2012). Fair Value and Audit Fees Fair Value and Audit Fees.

Griffith, E. E. . J. S. H. \& K. K. (2015). Audits of Complex Estimates as Verification of Management Numbers: How Institutional Pressures Shape Practice. Contemporary Accounting Research, 32.

Hidayat, A. (2014). No Interprestasi Regresi Data Panel StataTitle. In Statistikian.

Ho, J. L., \& Kang, F. (2013). Auditor choice and audit fees in family firms: evidence from the S\&P 1500. Auditing: A Journal of Practice \& Theory, 32(4).

Hoitash, R.;Markelevich, A;Barragato, C. . (2007). Auditor Fees and Audit Quality. Managerial Auditing Journal, 22(8), 761-786.

Jensen, M., C. \& Meckling. W., H. (1976). Theory of The Firm: Managerial Behavior, Agency Cost, and Ownership Structure. Journal of Financial Economics, 3(4).

Khan, A.; Muttakin, M. B \& Siddique, J. (2015). Audit Fees, Auditor Choice and Stakeholder Influence: Evidence From A Family-Firm Dominated Economy. The British Accounting Review, 47.

Khikia, H. Y. (2015). Determinants of Audit Fees: Evidence from JordanNo Title. Accounting and Finance Research, 4(1).

Kumarasiri, J. \& Fisher, R. (2011). Auditors' Perceptions of Fair-Value Accounting: Developing Country Evidence. International Journal of Audit, 15(1).

La Porta, R.; Lopez-de-Silanes, F.; \& Shleifer, A. (1999). Corporate Ownership Around The World. Journal of Finance, 54(2). 
Larcker, D. F., \& R. (2004). Fees Paid to Audit Firms, Accrual Choices, and Corporate Governance. Journal of Accounting Research, 42(3), 625-628.

Meshari, O. (2008). The Pricing of Audit Services: Evidence from Kuwait. Managerial Auditing Journal, 23(7).

Nuryani, N \& Samsudiono, I. (2013). Pelaporan Kerugian Penurunan Nilai Goodwill serta Dampaknya Terhadap Nilai Perusahaan. Jurnal Riset Akuntansi Dan Keuangan, 2(3).

Paramita, M. (2016). Pengaruh Konvergensi Ifrs, Ukuran Perusahaan, Kompleksitas Perusahaan Dan Spesialisasi Industri Auditor Terhadap Fee Audit.

Ramadhani, N. E. (2016). Analisis Determinasi Keputusan Revaluasi Aset Tetap (Studi Perbandingan Perusahaan Manufaktur di Indonesia dan Singapura Tahun 2013-2015). In Naskah Publiksi.

Simunic, D. A. N. A. (1980). The Pricing of Audit Services: Theory and Evidence. 18(1).
Tysiac, K. (2016). Audit Fee Increases Varied Based On Size, Type of Auditee. Journal of Accountancy.

Veronica, S., \& Anggraita, V. (2016). Impact of Abnormal Audit Fee to Audit Quality: Indonesian Case Study. 6(1), 72-78. https://doi.org/10.5923/j.economics.20160601. 09

Yao D., F; Percy, M.; \& Hu, F. (2015). Fair Value Accounting For Non-Current Assets and Audit Fees: Evidence From Australian Companies. Journal of Contemporary Accounting \& Economics, 11.

Yao D., F; Percy, M. \& Hu, F. (2015). Fair Value Accounting For Non-Current Assets and Audit Fees: Evidence From Australian Companies. Journal of Contemporary Accounting \& Economics, 11.

Yuniarti, R. (2011). Audit Firm Size, Audit Fee and Audit Quality. Journal of Global Management, 2(1). 